\title{
PROCERA: Institucionalidade, Subsídio e Eficácia
}

\author{
PROCERA: Institutionality, subsidy and effectiveness
}

GERVÁSIO CASTRO DE REZENDE*,*

RESUMO: Este artigo apresenta os resultados de uma pesquisa sobre a eficácia do Programa Especial de Crédito para Reforma Agrária (PROCERA). Começa mostrando a recente evolução dos desembolsos dentro do programa, as fontes de recursos e a taxa de subsídios. Em seguida, prossegue discutindo os objetivos do programa e propondo uma medida de sua eficácia. Além disso, argumenta-se que, devido à alta taxa de subsídios e à estrutura institucional do programa, que gera a crença por parte do mutuário de que o empréstimo não deve ser pago, a eficácia do programa deve ser muito baixa. Isso significa que a maior parte do crédito é usada para comprar bens de consumo ou aumentar a produção para autoconsumo, em vez de aumentar a produção voltada para o mercado. Também são apresentadas algumas evidências empíricas a favor dessa hipótese.

PALAVRAS-CHAVE: Reforma agrária; distribuição de renda; propriedade da terra.

ABSTRACT: This paper presents the results of a research on the efficacy of the Special Program of Credit for Agrarian Reform (PROCERA). It begins by showing the recent evolution of disbursements within the Program, the sources of funds and the subsidy rate. It then proceeds by discussing the objectives of the Program and proposing a measure of its efficacy. In addition to that, it is argued that, due to the high subsidy rate and the Program's institutional framework, that generates the belief on the part of the borrower that the loan is not to be paid, the Program's efficacy must be very low. This means that most credit is used to buy consumer goods or to increase production for self-consumption, instead of increasing production geared to the market. Some empirical evidence in favor of this hypothesis is also presented.

KEYWORDS: Land reform; income distribution; land ownership.

JEL Classification: Q18; O13; Q15.

\footnotetext{
* Professor da Universidade Federal Fluminense - UFF, Rio de Janeiro/RJ, Brasil. E-mail: gcrezende@ terra.com.br.

** Pesquisador associado do IPEA/DIPES, Rio de Janeiro. Além de fornecer infraestrutura ao autor, o IPEA solicitou e conseguiu várias informações no Banco do Brasil, Banco Central, BNB e BASA. Marcos Stefan Mendonça Fazecas colaborou como estagiário e Luciano Carneiro, Chefe do Departamento de Apoio ao Desenvolvimento e Secretário Executivo da Comissão Nacional do PROCERA, contribuiu com informações e esclarecimentos muito valiosos.
} 


\section{INTRODUÇÃO}

O Programa de Crédito Especial para Reforma Agrária (PROCERA) foi criado pelo Conselho Monetário Nacional em 1985, tendo por base o Voto CMN 046/ 85, do presidente do BNDES, órgão ao qual ficou afeto o Programa. Segundo esse Voto, o PROCERA deveria propiciar "a formação de novos produtores - individuais ou em formas associativas - devidamente emancipados, capazes de se beneficiarem, oportunamente, dos diferentes instrumentos de política de desenvolvimento rural, inclusive do crédito rural regular, a serem acionados pelo Poder Público (...)".

Como parte de um programa mais amplo de pesquisa de avaliação da reforma agrária brasileira, no âmbito de um convênio entre a FAO e o INCRA, este trabalho pretende apresentar uma avaliação do PROCERA, com ênfase nos seguintes aspectos: (1) formação dos saldos devedores e da taxa de subsídio; (2) institucionalidade com respeito à obtenção dos recursos, cobertura dos subsídios e assunção do risco de inadimplência; (3) mecanismos de seleção de projetos e de cobrança da dívida; e (4) implicações da política de subsídio e da institucionalidade do Programa para sua eficácia em termos de elevar a renda do assentado e contribuir para sua emancipação.

O trabalho está organizado em 8 seções, incluindo esta introdução. Na Seção 2, mostra-se como evoluíram as operações contratadas dentro do PROCERA para o Brasil e regiões, por fontes de recursos, no período 1993/97. Para fins de comparação, foram incluídas também nessa seção as informações sobre o "crédito de implantação". A Seção 3 explica como se formava o subsídio ao Programa antes do Plano Real e a mudança introduzida pelo Governo após a estabilização monetária. A Seção 4 usa dados especialmente coletados no Banco Central e no Banco do Nordeste que descem a um nível de detalhe maior sobre as operações do PROCERA e servem para revelar algumas facetas críticas do Programa. A Seção 5 procura mostrar a importância, para a compreensão do PROCERA, de sua vinculação aos Fundos Constitucionais. A Seção 6 propõe uma medida de eficácia do PROCERA e argumenta que a eficácia do Programa, assim definida, é certamente muito baixa. A Seção 7 explica por que não é apresentado um teste empírico inicialmente previsto, e cita dados de outra pesquisa que corroboram a hipótese do trabalho. A Seção 8 resume as principais conclusões.

\section{A EVOLUÇÃO RECENTE DAS OPERAÇÕES DO PROCERA}

A Tabela 1 apresenta o valor das operações contratadas no PROCERA para o total do Brasil, segundo as fontes de recursos, no período 1993/97. A tabela inclui, ainda, o valor do "crédito de implantação" no mesmo período. Nos anos de 1996 e 1997, o valor total das operações do PROCERA foi, em média, de US\$ 207 milhões por ano; no triênio anterior (1993/95) esse valor médio anual foi de apenas US\$ 88,5 milhões, implicando um aumento de $134 \%$. Um crescimento maior ainda 
verificou-se com o crédito de implantação, se bem que nesse caso a alta iniciouse já em 1994. ${ }^{1}$

A Tabela 2 desagrega as informações da Tabela 1 por regiões, mas só cobre os anos de 1995 a 1997. Nota-se que há uma clara associação entre a fonte de recursos utilizada e a região beneficiada: as fontes orçamentárias (OGU-INCRA e Tesouro) são destinadas às regiões Sul e Sudeste, enquanto os recursos dos Fundos Constitucionais são alocados às respectivas regiões visadas. ${ }^{2}$ Quando o PROCERA só contava com fontes orçamentárias (FINSOCIAL, no tempo do BNDES, e OGU INCRA, após a assunção pelo Banco do Brasil do papel de gestor), esses recursos eram distribuídos por todas as regiões. O processo de concentração somente nas regiões Sul e Sudeste iniciou-se em 1992, quando se dá a vinculação parcial dos Fundos Constitucionais ao PROCERA. ${ }^{3}$

Tabela 1: PROCERA - Valor Total das Operações Contratadas Segundo Fontes de Recursos, e Crédito de Implantação, 1993/97 (US\$ milhões)

\begin{tabular}{lccccc}
\hline Fontes & 1993 & 1994 & 1995 & 1996 & 1997 \\
\hline TOTAL PROCERA & 88.3 & 82.6 & 94.6 & 223.7 & 190.0 \\
OGU- INCRA & 15.9 & 19.8 & 30.5 & 78.9 & 46.6 \\
Tesouro & - & - & 6.3 & 22.2 & - \\
FCO & 16.3 & 25.0 & 18.8 & 18.1 & 33.0 \\
FNE & 24.4 & 23.5 & 32.0 & 81.4 & 92.3 \\
FNO & 31.7 & 14.3 & 7.0 & 23.1 & 18.1 \\
CRÉDITO DE IMPLANTAÇÃO & 4.5 & 18.8 & 52.1 & 71.0 & 135.1 \\
\hline
\end{tabular}

Fonte: INCRA.

Tabela 2: PROCERA - Valor das Operações Contratadas por Fontes de Recursos e Regiões, 1995/97 (US\$ milhões)

\begin{tabular}{lccccccc}
\hline \multirow{2}{*}{$\begin{array}{l}\text { Regiões } \\
\text { e Anos }\end{array}$} & \multicolumn{7}{c}{ Fontes de Recursos } \\
\cline { 2 - 8 } & & OGU INCRA & Tesouro & FCO & FNE & FNO & Total \\
\hline Sul & 1995 & 16.2 & 2.2 & - & - & - & 18.4 \\
& 1996 & 50.7 & 17.7 & - & - & - & 68.4 \\
& 1997 & 22.4 & - & - & - & - & 22.4 \\
\hline & & & & & & continua na página seguinte
\end{tabular}

\footnotetext{
${ }^{1}$ Note-se que, segundo dados do Banco Central (Sistema RECOR), recursos do FAT no montante de US\$ 21 milhões também foram aplicados no PROCERA em 1996

${ }^{2}$ Os recursos do FAT, mencionados no rodapé anterior, também foram aplicados apenas nas regiões Sudeste e Sul.

${ }^{3}$ O PROCERA passou a receber $10 \%$ dos Fundos Constitucionais com base na Portaria Interministerial $\mathrm{n}^{\circ} 36$, de 6.2.92, e posteriormente na Lei $\mathrm{n}^{\circ} 9.126$, de 10.11 .95 , cujo artigo $7^{\circ}$ obriga os Bancos administradores a aplicar 10\% dos Fundos Constitucionais no PROCERA.
} 


\begin{tabular}{|c|c|c|c|c|c|c|c|}
\hline \multirow[t]{3}{*}{ Sudeste } & 1995 & 11.5 & 4.1 & \multicolumn{3}{|c|}{1.1} & 16.7 \\
\hline & 1996 & 21.0 & 3.6 & & & & 24.6 \\
\hline & 1997 & 15.4 & & & & & 15.4 \\
\hline \multirow[t]{3}{*}{ Centro-Oeste } & 1995 & 0.2 & & 18.8 & & & 19.0 \\
\hline & 1996 & & & 18.1 & & & 18.1 \\
\hline & 1997 & 1.7 & & 33.0 & & & 34.8 \\
\hline \multirow[t]{3}{*}{ Norte } & 1995 & 2.1 & & & & 7.0 & 9.1 \\
\hline & 1996 & 0.8 & & & & 23.1 & 24.0 \\
\hline & 1997 & 3.7 & & & & 18. 1 & 21.8 \\
\hline \multirow[t]{3}{*}{ Nordeste } & 1995 & 0.5 & & & 30.9 & & 31.4 \\
\hline & 1996 & 0.4 & 0.9 & & 76.9 & & 78.1 \\
\hline & 1997 & 3.4 & & & 91.6 & & 95.0 \\
\hline
\end{tabular}

Fonte: INCRA.

Essa utilização dos Fundos Constitucionais como fonte de recursos do PROCERA explica a grande expansão ocorrida no Programa nos últimos anos. Pode-se ver, pela Tabela 1, que, já no primeiro ano completo de sua utilização (1993), esses Fundos contribuíram com $82 \%$ do total de recursos do PROCERA; em 1994, essa percentagem foi de 76\%; em 1995, 61\%; em 1996 (quando as fontes orçamentárias aumentaram substancialmente, contando inclusive com o Orçamento do Tesouro, e, como veremos na Seção 4, também com os recursos do FAT) foi de 54,8\%; e, em 1997, voltou a mostrar seu predomínio, com $75,4 \%$.

\section{SALDOS DEVEDORES E SUBSÍDIO NO}

\section{PROCERA ANTES E DEPOIS DO PLANO REAL}

A Tabela 3 apresenta os saldos devedores no Banco do Brasil correspondentes às aplicações com recursos do OGU-INCRA, juntamente com os valores contratados em cada ano, repetidos da Tabela 1.

Tabela 3: PROCERA - Saldos Devedores e Valores Contratados no Banco do Brasil com Recursos do Orçamento do INCRA, 1991/97 (US\$ milhões)

\begin{tabular}{ccc}
\hline Anos & Valores Contratados no Ano & Saldos em 31.12 \\
\hline 91 & 10.3 & 5.1 \\
92 & 19.1 & 8.3 \\
93 & 15.9 & 6.8 \\
94 & 19.8 & 21.7 \\
95 & 30.5 & 52.4 \\
96 & 78.9 & 116.6 \\
97 & 46.6 & 187.0 \\
\hline
\end{tabular}

Fonte: Banco do Brasil. 
Pode-se ver que, até 1993, o saldo devedor não crescia junto com o volume de aplicações; de fato, o saldo permaneceu praticamente constante (no valor médio de US\$ 6,7 milhões) entre 31.1.91 e 31.12.93, embora nesse interregno (anos de 1992 e 1993) tivessem sido aplicados US\$ 35 milhões. Se a dívida tivesse acompanhado os valores concedidos aos assentados, o saldo devedor em 31.12.93 deveria ter atingido cerca de US\$ 40 milhões, quase 6 vezes o valor de US\$ 6,8 milhões efetivamente registrado como dívida no Banco do Brasil.

Pode-se ver, entretanto, que essa dissociação entre o saldo devedor e o fluxo de tomada de empréstimos desaparece a partir de 1994: entre 31.12.93 e 31.12.94 o saldo aumenta de US\$14,9 milhões, refletindo as operações de US\$ 19,8 milhões em 1994; entre 31.12.94 e 31.12.95 o saldo aumenta de US\$ 30,7 milhões, quase igual ao volume de aplicações em 1995 (US\$ 30,5 milhões); essa conexão entre variação do saldo e fluxo de aplicações só não se verifica em 1997, quando o saldo aumenta (em relação a 1996) muito mais do que o volume de operações no ano (US\$ 70,4 milhões contra US\$ 46,6 milhões).

Essa mudança de comportamento do saldo devedor vis-à-vis o fluxo de aplicações aparece com muita nitidez nos Gráficos 1 e 2, onde são comparadas, para os períodos de janeiro de 1993 a junho de 1994 (Gráfico 1) e de junho de 1994 a junho de 1996 (Gráfico 2), as curvas dos saldos devedores efetivos com as dos saldos obtidos através da adição, ao saldo devedor no início de cada período, das sucessivas aplicações mensais. É evidente que houve uma mudança drástica, começando em julho de 1994, na relação entre saldo devedor e volume de aplicações no PROCERA. Esse saldo devedor passou efetivamente a refletir o fluxo de aplicações somente após o Plano Real; antes, era como se as aplicações se evaporassem, sem formarem dívidas, sendo, assim, verdadeiras doações.

Grafico 1: PROCERA - Saldos Devedores Efetivos e Saldos Calculados, Recursos do OGU-INCRA - Período jan/93-jun/94

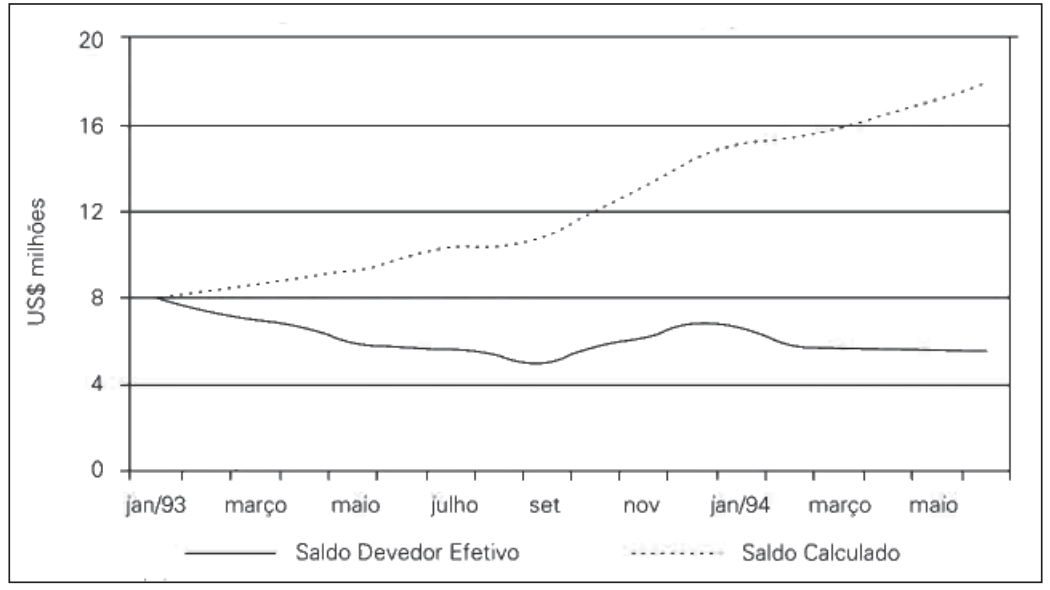

Fonte: Banco Central do Brasil. 
Gráfico 2: PROCERA - Saldos Devedores Efetivos e Saldos Calculados, Recursos do OGU-INCRA - Período jun/94-jun/96

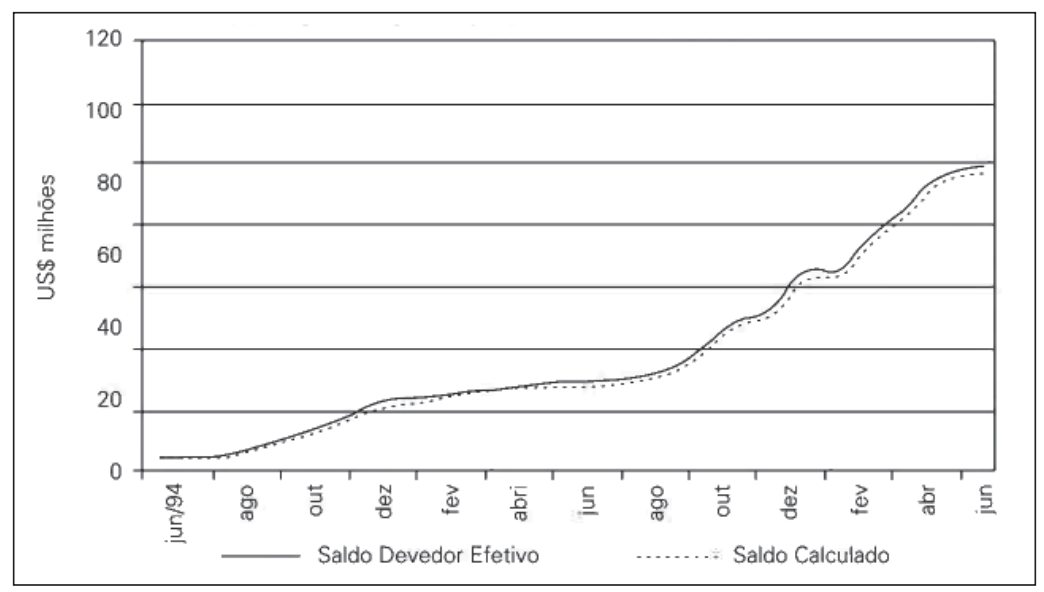

Fonte: Banco Central do Brasil.

A explicação dessa mudança de comportamento é simples: o saldo devedor em termos reais no final do mês $t$ era originalmente calculado pela fórmula (onde deixamos de lado a taxa de juros):

$$
\frac{\mathrm{S}_{\mathrm{t}}}{\left(1+\mathrm{P}_{\mathrm{t}}\right)}=\mathrm{E}_{\mathrm{t}}+\left[\mathrm{S}_{\mathrm{t}-1-}\left(1+0.5 \mathrm{p}_{\mathrm{t}}\right)\right] /\left(1+\mathrm{p}_{\mathrm{t}}\right)
$$

onde: $S_{t}=$ saldo devedor nominal no final do mês t;

$\mathrm{S}_{\mathrm{t}-1}=$ idem no mês $\mathrm{t}-1$;

$\mathrm{P}_{\mathrm{t}}=$ taxa de inflação(= correção monetária) no mês t;

$\mathrm{E}_{\mathrm{t}}=$ novos empréstimos no mês $\mathrm{t}$.

Essa era a dívida atribuída ao tomador de crédito. Como a expressão $\left(1+0.5 \mathrm{p}_{\mathrm{t}}\right)$ $/\left(1+p_{t}\right)$ é sempre menor que 1 , e se reduz com $P_{t}$ torna-se possível que, não obstante $E_{t}>O, S_{t}\left(1+p_{t}\right)$ se reduza, como acontecia antes do Plano Real. É claro que, após o Plano Real, com queda abrupta de $\mathrm{P}_{\mathrm{t}}$, o subsídio implícito nesse mecanismo de cálculo do saldo devedor reduziu-se violentamente, e o saldo devedor em t passou, agora, a ser o saldo devedor em t-1 mais o valor dos empréstimos concedidos durante t, exatamente como aparece no Gráfico 1. Para compensar o tomador de crédito, o Governo passou então a dar um "rebate" de 50\% sobre as amortizações do principal e juros, mas só apropriado pelo agricultor contra a liquidação das parcelas.

Embora esse rebate ainda constitua um subsídio muito elevado, a mudança em relação à situação anterior foi drástica. No quadro de alta inflação antes do Plano Real, a cobrança de apenas $50 \%$ da correção monetária, em empréstimos de prazo de 7 anos e 2 de carência, como era a regra no PROCERA, fazia com que o valor efetivamente pago, no final do empréstimo, fosse muito pequeno. Para se ter uma ideia disso, vale notar que, segundo cálculos gentilmente cedidos ao autor por 
Gilson Bittencourt, do Departamento Intersindical de Estudos Rurais (DESER), uma inflação de $20 \%$ ao mês faz com que um empréstimo de $\mathrm{R} \$ 7.650,00$, com 7 anos de prazo e 2 de carência e cobrança de $50 \%$ da correção monetária e zero de juros (para simplificar), seja totalmente pago, em termos reais, com $\mathrm{R} \$ 243,32$ (apenas 3\% do valor do empréstimo), sendo que a última parcela equivaleria a nada menos que R $\$ 0,85$, o que justifica plenamente a voz corrente entre os assentados de que "o PROCERA se pagava com a venda de uma galinha".

Além disso, como pode-se notar com a ajuda da Tabela 3 e do Gráfico 2, após o Plano Real a dívida passou a manter o seu valor real, e o subsídio só é apropriado se ela for paga, mesmo com rebate. Antes, a inflação sozinha derrubava a dívida, bastando que o agricultor esperasse o tempo passar.

\section{AS APLICAÇÕES DOS RECURSOS DO PROCERA POR FINALIDADES E TIPOS DE EMPRÉSTIMOS}

As Tabelas 4 a 7 mostram, para o período recente, o valor total e o valor médio das operações do PROCERA por finalidade. O fato que mais fica ressaltado nessas tabelas é o crescimento abrupto do custeio agrícola nas regiões Sul e Sudeste em 1996 (mantendo-se elevado em 1997) e nas regiões Centro-Oeste e Nordeste, em 1997. ${ }^{4}$ Isso se deveu à duplicação do valor do crédito de custeio (de R \$1.000,00 para $\mathrm{R} \$ 2.000,00$ ) e extensão, a ele, do rebate de $50 \%$ do principal e juros, no período de um ano apenas. O assentado, a partir de 1996, continuou podendo tomar $\mathrm{R} \$ 2.000,00$ de custeio no $1^{\circ}$ ano, acoplado a um crédito de investimento e pago no mesmo prazo deste, mas passou a poder tomar mais $\mathrm{R} \$ 2.000,00$ todo ano, a partir do $2^{\circ}$ ano, pagando, no vencimento um ano depois, apenas $\mathrm{R} \$ 1.000,00$. É fácil ver que um sistema como esse permite ao assentado acumular um ganho substancial ao cabo de algum tempo, sem correr qualquer risco. ${ }^{5}$

\footnotetext{
${ }^{4}$ Não são apresentados os dados relativos à Região Norte, obtidos do BASA, porque eles divergiam muito dos valores obtidos do INCRA, incluídos nas Tabelas 1e 2 .

${ }^{5}$ Ao cabo de 10 anos, por exemplo, o assentado que tomar o crédito de custeio todo ano a partir do $1^{\circ}$ terá um ganho financeiro de $\mathrm{R} \$ 9.000,00$. O banco poderá, ainda, facilitar a vida desse assentado fazendo coincidir o vencimento de um empréstimo com a contratação do próximo, o que é conhecido como "mata-mata", procedimento que fere as normas do crédito rural, já que contribui para converter o crédito rural favorecido numa mera operação de ganho financeiro.
} 
Tabela 4: PROCERA - Número e Valor das Operações Contratadas,

Segundo a Finalidade - 1993/97 - Região Sul

\begin{tabular}{ccccc|ccc}
\hline & \multicolumn{3}{c|}{ Valor das Operações (em US\$ mil) } & \multicolumn{3}{c}{ Valor Médio das Operações (em US\$) } \\
\cline { 2 - 8 } Ano & $\begin{array}{c}\text { Custeio } \\
\text { Agrícola }\end{array}$ & $\begin{array}{c}\text { Invest. } \\
\text { Agrícola }\end{array}$ & $\begin{array}{c}\text { Invest. } \\
\text { Pecuário }\end{array}$ & Total & $\begin{array}{c}\text { Custeio } \\
\text { Agrícola }\end{array}$ & $\begin{array}{c}\text { Invest. } \\
\text { Agrícola }\end{array}$ & $\begin{array}{r}\text { Invest. } \\
\text { Pecuário }\end{array}$ \\
\hline 1993 & 62 & 24.813 & 2.945 & 27.820 & 456 & 7.431 & 3.548 \\
1994 & 42 & 21.598 & 3.839 & 25.478 & 1.444 & 3.428 & 4.256 \\
1995 & 310 & 16.336 & 4.735 & 21.381 & 864 & 5.067 & 4.344 \\
1996 & 11.591 & 35.755 & 17.567 & 64.914 & 3.229 & 13.768 & 6.817 \\
1997 & 10.258 & 6.125 & 3.774 & 20.157 & 1.845 & 4.480 & 11.795 \\
\hline
\end{tabular}

Fonte: Banco Central do Brasil, Sistema RECOR.

Tabela 5: PROCERA - Número e Valor das Operações Contratadas,

Segundo a Finalidade - 1993/97 - Região Sudeste

\begin{tabular}{|c|c|c|c|c|c|c|c|}
\hline \multirow[b]{2}{*}{ Ano } & \multirow{2}{*}{$\begin{array}{c}\text { Valor } \\
\text { Custeio } \\
\text { Agrícola }\end{array}$} & \multicolumn{3}{|c|}{ das Operações (em US\$ mil) } & \multicolumn{3}{|c|}{ Valor Médio das Operações (em US\$) } \\
\hline & & $\begin{array}{c}\text { Invest. } \\
\text { Agrícola }\end{array}$ & $\begin{array}{c}\text { Invest. } \\
\text { Pecuário }\end{array}$ & Total & $\begin{array}{l}\text { Custeio } \\
\text { Agrícola }\end{array}$ & $\begin{array}{c}\text { Invest. } \\
\text { Agrícola }\end{array}$ & $\begin{array}{l}\text { Invest. } \\
\text { Pecuário }\end{array}$ \\
\hline 1993 & 36 & 4.604 & 1.332 & 5.972 & 1.562 & 2.167 & 1.597 \\
\hline 1994 & 442 & 4.232 & 3.799 & 8.473 & 2.242 & 3.082 & 1.588 \\
\hline 1995 & 151 & 10.217 & 9.588 & 19.956 & 541 & 7.051 & 2.755 \\
\hline 1996 & 4.968 & 14.720 & 19.173 & 38.860 & 1.641 & 6.245 & 5.288 \\
\hline 1997 & 5.472 & 4.146 & 4.618 & 14.236 & 1.518 & 7.404 & 4.241 \\
\hline
\end{tabular}

Fonte: Banco Central do Brasil, Sistema RECOR.

Tabela 6: PROCERA - Número e Valor das Operações Contratadas, Segundo a Finalidade - 1993/97 - Região Centro-Oeste

\begin{tabular}{|c|c|c|c|c|c|c|c|}
\hline \multirow[b]{2}{*}{ Ano } & \multirow{2}{*}{$\begin{array}{c}\text { Valor } \\
\text { Custeio } \\
\text { Agrícola }\end{array}$} & \multicolumn{3}{|c|}{ das Operações (em US\$ mil) } & \multicolumn{3}{|c|}{ Valor Médio das Operações (em US\$) } \\
\hline & & $\begin{array}{c}\text { Invest. } \\
\text { Agrícola }\end{array}$ & $\begin{array}{l}\text { Invest. } \\
\text { Pecuário }\end{array}$ & Total & $\begin{array}{l}\text { Custeio } \\
\text { Agrícola }\end{array}$ & $\begin{array}{c}\text { Invest. } \\
\text { Agrícola }\end{array}$ & $\begin{array}{l}\text { Invest. } \\
\text { Pecuário }\end{array}$ \\
\hline 1993 & 407 & 3.728 & 26.610 & 30.745 & 443 & 3.796 & 10.080 \\
\hline 1994 & 157 & 5.919 & 15.583 & 21.659 & 129 & 5.542 & 3.000 \\
\hline 1995 & 570 & 6.520 & 16.389 & 23.478 & 492 & 3.608 & 3.356 \\
\hline 1996 & 1.816 & 2.258 & 19.617 & 23.691 & 758 & 2.124 & 2.606 \\
\hline 1997 & 6.898 & 8.729 & 20.106 & 35.732 & 1.123 & 3.362 & 3.453 \\
\hline
\end{tabular}

Fonte: Banco Central do Brasil, Sistema RECOR.

Tabela 7: PROCERA - Valor Total e Valor Médio das Operações Contratadas

Segundo a Finalidade - 1995/97 - Região Nordeste

\begin{tabular}{ccccc|ccc}
\hline & \multicolumn{2}{c|}{ Valor } & \multicolumn{2}{c|}{ das Operações (em US\$ mil) } & \multicolumn{3}{c}{ Valor Médio das Operações (em US\$) } \\
\cline { 2 - 8 } Ano & $\begin{array}{c}\text { Custeio } \\
\text { Agrícola }\end{array}$ & $\begin{array}{c}\text { Invest. } \\
\text { Agrícola }\end{array}$ & $\begin{array}{c}\text { Invest. } \\
\text { Pecuário }\end{array}$ & Total & $\begin{array}{c}\text { Custeio } \\
\text { Agrícola }\end{array}$ & $\begin{array}{c}\text { Invest. } \\
\text { Agrícola }\end{array}$ & $\begin{array}{c}\text { Invest. } \\
\text { Pecuário }\end{array}$ \\
\hline 1995 & 2.648 & 7.904 & 18.824 & 29.376 & 2.412 & 7.803 & 4.195 \\
1996 & 4.641 & 22.544 & 54.631 & 81.816 & 1.248 & 5.845 & 5.482 \\
1997 & 17.093 & 21.857 & 60.536 & 99.486 & 1.208 & 8.430 & 7.448 \\
\hline
\end{tabular}

Fonte: Banco do Nordeste. 
As Tabelas 8 a 10, por sua vez, mostram para as regiões Sul, Sudeste e CentroOeste o montante, por faixa de tamanho, dos “empréstimos coletivos", que reúnem os empréstimos concedidos a 2 ou mais assentados e aqueles destinados à integralização de quotas-partes de cooperativas. Pela comparação com a última linha dessas tabelas, pode-se ter uma ideia da importância relativa dessas operações no PROCERA: no triênio $1995 / 97$ elas representaram nada menos que $56 \%$ do valor total das operações na região Sul, $25 \%$ na região Sudeste e $28 \%$ na região Centro Oeste.

Tabela 8: Região Sul - Valor das Operações Coletivas por

Faixa de Tamanho e Valor Total das Operações, 1995/97 |(em mil R\$)

\begin{tabular}{lccc}
\hline \multicolumn{1}{c}{ Faixas de Tamanho dos Empréstimos } & 1995 & 1996 & 1997 \\
\hline menos de 5 & 364 & 1.383 & 829 \\
5 a menos de 10 & 856 & 3.968 & 2.651 \\
10 a menos de 20 & 3.474 & 3.697 & 2.542 \\
20 a menos de 50 & 2.263 & 14.588 & 3.490 \\
mais de 50 & 3.581 & 14.785 & 1.452 \\
Total & 10.538 & 38.421 & 10.964 \\
Valor Total das Operações & 21.381 & 64.914 & 20.157 \\
\hline
\end{tabular}

Fonte: Banco Central.

Tabela 9: Região Sudeste - Valor das Operações Coletivas por

Faixa de Tamanho e Valor Total das Operações, 1995/97 (em mil R\$)

\begin{tabular}{lccc}
\hline Faixas de Tamanho dos Empréstimos & 1995 & 1996 & 1997 \\
\hline menos de 5 & 34 & 254 & 137 \\
5 a menos de 10 & 179 & 428 & 481 \\
10 a menos de 20 & 260 & 720 & 405 \\
20 a menos de 50 & 407 & 1.653 & 488 \\
mais de 50 & 5.251 & 4.830 & 2.734 \\
Total & 6.131 & 7.885 & 4.245 \\
Valor Total das Operações & 19.956 & 38.860 & 14.236 \\
\hline
\end{tabular}

Fonte: Banco Central.

Tabela 10: Região Centro-Oeste - Valor das Operações Coletivas por

Faixa de Tamanho e Valor Total das Operações, 1995/97 (em mil R\$)

\begin{tabular}{lccc}
\hline Faixas de Tamanho dos Empréstimos & 1995 & 1996 & 1997 \\
\hline menos de 5 & 425 & 1,045 & 457 \\
5 a menos de 10 & 26 & 679 & 1.616 \\
10 a menos de 20 & 77 & 629 & 1.303 \\
20 a menos de 50 & 3.223 & 3.569 & 4.222 \\
mais de 50 & 1.339 & 1.054 & 3.277 \\
Total & 5.092 & 6.977 & 10.875 \\
Valor Total das Operações & 23.478 & 23.691 & 35.732 \\
\hline
\end{tabular}

Fonte: Banco Central. 
A Tabela 11, por sua vez, mostra, para o Nordeste, como as operações de custeio e investimento se distribuíram por faixas de tamanho (em valor do empréstimo). Considerando toda operação de valor superior a $\mathrm{R} \$ 10.000,00$ como uma operação coletiva, conclui-se que essas operações absorveram $30 \%$ do custeio agrícola e 38\% do investimento, no triênio 1995/97.

Essas operações ditas "coletivas", assim como as decorrentes de formação de uma cooperativa ou agroindústria, geram uma dívida para o assentado (para o que surgiu até a figura do "teto 2", para a criação das cooperativas) que dificilmente poderá ser paga. No caso das operações “coletivas”, são tantas as incertezas e os condicionantes quanto ao efeito dessas operações sobre a capacidade produtiva e a renda individual e, assim, sobre a capacidade de pagamento de cada assentado, que só a expectativa de não-pagamento dessa dívida faz o assentado contraí-la. O mesmo se dá com o endividamento individual dos assentados como meio para a criação de cooperativas e agroindústrias. Um instituto - o empréstimo bancário para a integralização de quotas-partes de cooperativas - comum nas áreas de agricultura familiar desenvolvida foi "copiado" para a reforma agrária, como se não houvesse um verdadeiro fosso entre uma realidade e a outra.

Tabela 11: Região Nordeste - Valor das Operações por Faixa de Tamanho

Segundo a Finalidade, 1995/97 (em mil R\$)

\begin{tabular}{l|cc|cc|cc}
\hline \multirow{2}{*}{$\begin{array}{c}\text { Faixas de Tamanho } \\
\text { dos Empréstimos }\end{array}$} & \multicolumn{2}{|c|}{1995} & \multicolumn{2}{c|}{1996} & \multicolumn{2}{c}{1997} \\
\cline { 2 - 7 } & Custeio & Investimento & Custeio & Investimento & Custeio & Investimento \\
\hline menos de 5 & 1.474 & 12.731 & 3.072 & 24.503 & 11.879 & 13.936 \\
5 a menos de 10 & 110 & 105 & 275 & 24.204 & 269 & 37.997 \\
10 a menos de 20 & 14 & 948 & 178 & 416 & 1.062 & 245 \\
20 a menos de 50 & 142 & 1.740 & 398 & 1.474 & 1.213 & 1.790 \\
mais de 50 & 907 & 11.204 & 557 & 22.171 & 2.669 & 28.425 \\
Total & 2.648 & 26.728 & 4.481 & 72.768 & 17.093 & 82.393 \\
\hline
\end{tabular}

Fonte: Banco do Nordeste.

\section{O PAPEL DOS FUNDOS CONSTITUCIONAIS DE FINANCIAMENTO}

Conforme mostrou-se na Seção 2, os Fundos Constitucionais de Financiamento tornaram-se a fonte principal dos recursos do PROCERA desde 1993. A relevância dessa contribuição dos Fundos Constitucionais não está apenas no fato óbvio de que o Programa obteve, assim, uma capacidade de mobilização de recursos incomparavelmente maior, mais ágil e mais segura do que se dependesse apenas do orçamento da União. ${ }^{6}$ Não se trata apenas de uma questão quantitativa. Os

\footnotetext{
${ }^{6}$ Como se sabe, esses Fundos são formados por 3\% do IR e do IPI. A STN repassou para esses Fundos, entre 1989 e 1998 (até agosto), um montante global de R \$13,6 bilhões, sendo R \$ 2,7 bilhões para o FCO, o mesmo para o FNO, e R \$ 8,2 bilhões para o FNE (valores em R \$ de agosto de 1998). Para mais informações, consulte MPO/SEPRE (1998)
} 
Fundos Constitucionais não estão sujeitos à disciplina orçamentária instituída para a política agrícola em geral desde 1988, a partir de quando os recursos orçamentários para concessão de crédito são alocados primeiro ao Orçamento das Operações de Crédito (OOC), administrado pela Secretaria do Tesouro, o qual compõe o OGU, e só depois são repassados aos agentes financeiros sob a forma de empréstimos, com subsídios previstos e também incluídos (na rubrica de "equalização de juros") no OOC. Os agentes financeiros assumem o risco das operações, ou seja, eles é que são os responsáveis pelos recursos perante o Tesouro. Não é por outro motivo que esses agentes, em tais condições, são muito exigentes de garantias na concessão dos agentes, em que é deles o risco. ${ }^{7}$

O ponto importante aqui é que os Fundos Constitucionais - e, por decorrência, o PROCERA - excluem-se dessa institucionalidade. Quanto ao risco operacional, este vinha sendo dos Bancos, com exceção das aplicações do PROCERA.

Entretanto, a MP 1.727, de 9/11/98, reduziu o risco dos Bancos nas operações dos Fundos para apenas 50\%, atribuindo aos Fundos os 50\% restantes de risco. Cabe notar, a propósito, que, segundo Oliveira (1997, p.185), tanto os recursos do OGUINCRA quanto dos Fundos não deveriam estar fora desse enquadramento institucional. Segundo ele,

"Tais recursos apresentam duas características básicas: provêm do Tesouro Nacional e são reembolsáveis. Nisso, aproximam-se dos que se destinam ao custeio agrícola, às operações da política de garantia de preços mínimos e à equalização de taxas do juros de crédito rural. Essa condição sugere (...) submetê-los a critérios orçamentários específicos, utilizado pelo OGU nos dias de hoje, no trato das operações de crédito."

Após historiar a criação desse enquadramento orçamentário - que, por sinal, afeta profundamente a execução da política agrícola, conforme analisado em Rezende e Silva (1993) - Oliveira (1997, p. 186) aponta que, no caso do PROCERA,

“é possível distinguir três tipos de subsídios, garantidos por medidas e normas, sem correspondente quantificação orçamentária: 1) 'rebate' da taxa de juros; 2) desencontro entre desembolso e amortização; e 3) assunção de inadimplência pelo 'Fundo Contábil'."

Segundo ainda Oliveira (1997, pp.187-8),

"Na hipótese de os recursos destinados ao PROCERA passarem a transitar, orçamentariamente, pelo OOC, deve-se atentar para as seguintes alterações:

\footnotetext{
${ }^{7}$ No caso do PRONAF, embora a fonte principal dos recursos seja o FAT (ou seja, não é orçamentária), o risco é do agente financeiro, e o Fundo tem de ser devidamente remunerado, o que decorre do art. 239, parágrafo $1^{\circ}$ da Constituição, que prescreve que os empréstimos do FAT sejam feitos "com critérios de remuneração que lhes preserve o valor”. Isso implica a equalização de juros pelo Tesouro Nacional.
} 
1) o volume anual de subsídios passa a ser estimado e orçado; com isso, torna-se explícito e suscetível de maior controle pela sociedade;

2) os agentes financeiros e os gestores do programa passam a se responsabilizar pelo risco das operações e a prestar contas ao Tesouro Nacional;

3) os recursos não passam pelo INCRA; vão direto do Tesouro ao Gestor do Fundo;

4) os agentes financeiros, automaticamente, passam a introduzir maior seletividade na concessão de crédito;

5) os custos do programa podem aumentar para cobrir o risco bancário. ${ }^{8}$

Além de escaparem desse enquadramento orçamentário, os Fundos Constitucionais sempre conseguiram escapar também das várias tentativas de ajuste fiscal e de reforma tributária, graças ao poder político das regiões beneficiadas. Para a equipe econômica (e, com certeza, boa parte do Governo Federal), os recursos carreados para esses Fundos são considerados perdidos e, por isso, a aplicação na reforma agrária não significa um ônus fiscal adicional. ${ }^{9}$ Ao contrário, essa aplicação deve até mesmo ser preferida, por atender a um reclamo nacional e em vista da "caixa preta" que representam as aplicações desses Fundos. ${ }^{10}$ Note-se, ainda, que não foi feita, até hoje, qualquer avaliação independente do efeito desses Fundos sobre o desenvolvimento das regiões beneficiadas; a este respeito, o IPEA (1998, p. 58) considera "imprescindível" que se proceda a "uma avaliação isenta, profunda e objetiva dos Fundos nestes seus já 10 anos de existência". É fácil também entender as sucessivas "ondas" de novos empréstimos ("teto 2", custeio anual com rebate de $50 \%$ ), e as constantes prorrogações do pagamento das parcelas, já que os Fundos têm novos recursos todo ano, forçando o PROCERA a descobrir continuamente novas formas de aplicação.

\footnotetext{
${ }^{8}$ Ver também Oliveira (1996), para um questionamento mais sistemático desse não-enquadramento no OOC dos recursos do PROCERA, inclusive os originários do OGU-INCRA.

${ }^{9}$ É interessante notar, a propósito, que, segundo Rezende e Silva (1993, p.38), as transferências da União para os Fundos "são classificadas, sob a ótica do Tesouro Nacional, como gastos a fundo perdido."

${ }^{10}$ Cálculos do MPO/SEPRE (1998, p. 50) indicam que, dos R \$ 13,6 bilhões repassados no período 1989/98, restou um patrimônio líquido de apenas R \$ 7,5 bilhões em agosto de 1998, sendo de se perguntar quanto disso será pago. (A propósito, note-se que, conforme noticiado na Gazeta Mercantil de 5/11/98, o Governo iria editar MP prorrogando dívidas junto aos Fundos no valor de R \$ 1,5 bilhões. Uma MP - no 1727, datada de 9/11/98 -de fato foi editada, reduzindo as taxas de juros em empréstimos a partir de 1/12/98, com extensão aos anteriores. Além disso, essa MP permite a renegociação de dívidas, com prorrogação por até 5 anos, sem multa por atraso.) Para se calcular o subsídio no período, é preciso, ainda, incluir os juros que o Governo pagou pela dívida que teve de ser acumulada por não estarem esses recursos disponíveis para outros gastos.
} 


\section{A EFICÁCIA DO PROCERA}

Como foi dito antes, o PROCERA foi instituído, em 1985, com o objetivo de viabilizar a "emancipação" dos assentados da reforma agrária, ou seja, torná-los independentes da ajuda do Governo, com a consequente titulação definitiva. O gasto do governo com o Programa seria compensado com a redução de despesas decorrente dessa "emancipação".

Ora, essa "emancipação" supõe que a atividade agrícola do assentado tenha se tornado viável economicamente, gerando renda capaz de satisfazer as necessidades do agricultor e sua família, e bem assim permitir uma poupança necessária para novos investimentos e contínua modernização produtiva.

Isso só é possível com a progressiva inserção do assentado no mercado, pelas seguintes razões: (1) a produção de subsistência impede maior grau de especialização produtiva e assim limita os ganhos de produtividade; (2) a produção para o mercado, com consequente sujeição às forças de concorrência, leva o agricultor à busca incessante de informações e de maior capacitação; e (3) só a produção mercantil e a consequente geração de renda monetária permite a satisfação mais plena das necessidades de consumo, que vão muito além do permitido pela agricultura de subsistência.

Ora, um programa especial de crédito acoplado à reforma agrária, se devidamente formulado, pode dar uma grande contribuição no sentido de fomentar o aumento da produção e da produtividade agrícolas do assentado, simultaneamente à sua maior integração ao mercado. As razões são as seguintes: (1) ele viabiliza o investimento necessário, ou seja, contorna a forte restrição de capital que caracteriza o público meta da reforma agrária; e (2) força a reorientação mercantil, ao criar um compromisso financeiro que só pode ser resgatado por meio de investimento na produção visando ao mercado; o crédito estaria, assim, cumprindo um papel de ariete na promoção da produção mercantil.

Note-se que esse problema de promover maior integração ao mercado se cinge aos assentados mais pobres - que são a maioria -, já que, para uma minoria proveniente de regiões de agricultura familiar desenvolvida, já se dá a integração ao mercado. Por outro lado, conforme aponta Garcia Jr. (1994, pp. 90-92), em situação de forte instabilidade e mesmo de nível alto de preços de alimentos, como no Nordeste, o agricultor pode preferir produzir ele mesmo o alimento básico (feijão, mandioca, milho), dificultando a transformação para a produção mercantil. Nesse caso, embora o crédito ainda assim possa promover uma maior integração ao mercado (via aumento do excedente comercializável desses bens), é claro que ele deve ser parte de um programa mais amplo, que ajude o agricultor a identificar oportunidades de investimento visando o mercado e que sejam viáveis.

A ênfase nesses aspectos econômicos, que marcou a proposta de criação do PROCERA e foi adotada neste trabalho, costuma ser cunhada criticamente de "produtivista” por alguns analistas. Entretanto, tal abordagem se justifica porque o sucesso econômico é pressuposto para que outros objetivos, mais diretamente de 
natureza social ou política, atribuíveis à reforma agrária, possam ser atingidos. Além do mais, como aponta Abramovay (1994, p. 137), a alocação de terra e outros recursos produtivos (inclusive a própria mão-de-obra do assentado) no programa de reforma agrária tem de ser justificada por algum tipo de eficiência econômica, "a menos que se definam os assentamentos sob um modelo próximo ao das reservas indígenas", onde "esta preocupação é inteiramente ausente", já que, segundo Abramovay, a sociedade brasileira não tem por que esperar mais, dessas reservas, do que a preservação cultural e ambiental.

Tendo em vista esse papel originalmente atribuído ao PROCERA, de contribuir para encurtar o tempo necessário à "emancipação" do assentado e tornando, assim, a reforma agrária um programa de sucesso, cabe estabelecer, para fins da presente avaliação do programa, a seguinte medida de eficácia:

$$
e=\frac{\text { aumento do investimento na produção mercantil }}{\text { tomada de crédito no PROCERA }}
$$

A capacidade do crédito atingir esse objetivo é limitada, contudo, na medida em que a taxa de retorno do investimento a ser financiado pode ser baixa e o risco alto. Além disso, a melhoria do consumo só ocorre no futuro, o que é um desestímulo adicional, já que a taxa de preferência intertemporal dos assentados, especialmente dos mais pobres, é muito alta.

O problema da baixa taxa de retorno tem duas alternativas de solução: (1) elevação da própria taxa de retorno e/ou redução do risco. Isso envolve investimentos públicos em treinamento e capacitação, melhoria de qualidade e de localização de terras, promoção de parcerias com as agroindústrias etc.; ou (2) concessão de subsídio ao crédito, na expectativa de que, assim, o investimento na produção para o mercado se torne rentável.

A opção exclusiva do PROCERA pelo subsídio, em vez de atuar também sobre a taxa de retorno, está presente também nos Fundos Constitucionais de Financiamento. Por exemplo, o FNE deve alocar $50 \%$ dos seus recursos ao semi-árido do Nordeste, região que, por suas carências de infra-estrutura e precariedade climática deveria ser a última a ser escolhida para uma política de desenvolvimento via crédito subsidiado. ( $\mathrm{O}$ único resultado que se consegue com isso é uma carteira de empréstimos "micada" no BNB, que supostamente deve arcar com o prejuízo.) Melhor seria aplicar esses recursos no próprio semi-árido mas de outra maneira, nem que seja a fundo perdido, numa política de desenvolvimento regional muito mais baseada em investimentos públicos, criadores de externalidades, como proposto em IPEA (1998).

O problema com o subsídio, e especialmente com uma taxa de subsídio muito alta, é que ele "chancela" uma baixa taxa de retorno. Na realidade, ele contribui para essa baixa taxa de retorno, não estimulando o agricultor a dar o melhor do seu esforço. Além disso, quando o subsídio estende-se ao próprio principal, como é o caso do PROCERA, o agricultor pode destinar os fundos do crédito à compra 
imediata de bens de consumo ou à produção de autoconsumo, já que, nesse caso, ele não precisa criar capacidade de pagamento futuro. ${ }^{11}$

Além de contar com alta taxa de subsídio sobre o principal e juros, o PROCERA tem sido marcado também pela certeza por parte dos assentados de que não é para ser pago. Ora, isso obviamente reforça o resultado acima, de utilização do empréstimo para consumo imediato ou produção para autoconsumo e não para investimento produtivo voltado para o mercado.

Para essa percepção generalizada de que o PROCERA não é para ser pago contribuem vários fatores. Em primeiro lugar, a própria experiência passada (anterior ao Plano Real), em que o mecanismo de formação da dívida permitia que ela fosse paga "com a venda de uma galinha". Isso certamente criou todo um conjunto de expectativas difíceis de serem alteradas. Em segundo lugar, a verdade é que algumas operações são tão mal concebidas que de fato são impagáveis, como se notou antes com relação aos "empréstimos coletivos" e às integralizações de quotas-partes de cooperativas. Em terceiro lugar, cabe destacar o papel das sucessivas prorrogações das dívidas passadas, ao mesmo tempo em que novos empréstimos são "bolados" e concedidos. ${ }^{12}$ Isso só piora o problema do endividamento, e reforça a impressão de que o Governo vai acabar dando anistias, como já fez no passado. Em quarto lugar, existe muita facilidade para o assentado, mesmo endividado, "passar" o lote e o novo assentado ainda ter acesso a novo PROCERA, já que o INCRA não tem capacidade de controle. ${ }^{13}$ Em quinto lugar, é preciso levar em conta a circunstância de que o Banco não corre risco - e nem poderia correr, aliás, numa situação em que ele tem de "acolher", segundo o cap. 15 das Normas de

\footnotetext{
${ }^{11}$ Note-se que esse "desvio" para o consumo ou para a produção de subsistência não é do mesmo tipo do "desvio" que se apontava na política de crédito rural subsidiado dos anos 70 e 80 . Esta última atingia principalmente agricultores mais capitalizados, muitas vezes com atividades múltiplas, e certamente sem as carências de consumo dos atuais assentados da reforma agrária. O "desvio" que se apontava consistia de aplicações não-agrícolas - no mercado financeiro ou em outros setores -, porque a taxa de retorno marginal dessas aplicações seria maior do que na agricultura. Mas seriam aplicações de capital, de qualquer maneira, não despesas em bens de consumo ou na agricultura de subsistência. Isso explica, aliás, que a medida de eficácia da política de crédito rural adotada por Sayad em sua conhecida análise era dada por e = investimento agrícola / crédito rural, cuja semelhança coma nossa medida de eficácia do PROCERA é óbvia.

${ }^{12}$ A última prorrogação de dívidas do PROCERA, no valor de R \$ 250 milhões, foi autorizada pelo Conselho Monetário Nacional em reunião do dia 6.11.98, conforme noticiado pela Gazeta Mercantil de 7 e 8.11.98. Documento interno do governo sobre a "reforma da reforma agrária", datado de 9 de março de 1999, afirma que o governo federal, em fins de 1998, decidiu "prorrogar por dez anos, incluindo três de carência, um estoque de dívidas de mais de $\mathrm{R} \$ 800$ milhões”.

${ }^{13}$ Bruno e Medeiros (1998), em outra pesquisa no âmbito do convênio FAO/INCRA, constataram um forte efeito do PROCERA de aumentar a evasão dos assentamentos, já que, segundo as entrevistas, assim se fugia da dívida. Além de "fugir" da dívida, o assentado ainda conseguia "passar" o lote, sendo de se perguntar se o novo assentado tem de assumir, nesse caso, a dívida, ou seja, se a venda do lote tem de ter a interveniência do Banco. Caso contrário, e se o novo assentado ainda tiver acesso a novo PROCERA, então entrar e depois sair dos assentamentos terá virado um grande negócio, graças ao PROCERA.
} 
Administração do PROCERA (março de 1997), as decisões de Comissões Estaduais, onde representantes dos assentados e do MST têm assento e voto. E last, but not least, cabe notar que todo o programa de reforma agrária padece desse problema de não se cobrar o que, por lei, deveria ser cobrado, conforme apontam Gasques e Villa Verde (1999). Isso inclui a terra, infra-estrutura, crédito de implantação etc. (Essa cobrança, como se sabe, está prevista para ocorrer somente quando da "emancipação" do assentado, que, por isso mesmo, não tem qualquer interesse em se titular ou se "emancipar". O próprio PROCERA deixa de estar disponível para os assentados que se emanciparem, conforme o art. 9 das Normas de Administração do Programa.)

Assim, começando pela alta taxa de subsídio concedido (inclusive sobre o principal), continuando pela falta de punição pelo não-pagamento da dívida por parte do assentado, prosseguindo pela indiferença do Banco quanto à qualidade dos projetos e à sua factibilidade, estendendo-se pela ausência de qualquer responsabilidade por parte da assistência técnica e completando-se pela absoluta falta de fiscalização, temos aí toda uma cadeia de causalidade que, ancorada na falta do desejável enquadramento orçamentário tanto dos recursos do INCRA quanto dos Fundos Constitucionais, impede, com toda a certeza, que o PROCERA atinja seus objetivos, tão importantes para o sucesso da reforma agrária no Brasil.

\section{EVIDÊNCIA EMPÍRICA SOBRE A EFICÁCIA DO PROCERA}

O projeto que deu origem a este trabalho pretendia utilizar as informações de uma pesquisa intitulada "Avaliação e Acompanhamento do Programa de Crédito Especial para a Reforma Agrária - PROCERA: 1986-1995", que contou com recursos da FINEP, do BID, da FAPESP e do INCRA (Jorge et alii, 1997), na qual aplicaram-se questionários a $5 \%$ dos assentados que obtiveram empréstimos em 1993, num total de 1.035 assentados em 9 estados.

Frustrando as expectativas iniciais de nossa pesquisa, entretanto, esses dados se revelaram completamente inadequados para um teste da hipótese acima de ineficácia do PROCERA. Os questionários limitaram-se aos assentados que tomaram crédito, e as informações coletadas não permitem sequer medir o impacto de diferentes níveis de crédito sobre a produção ou o investimento, não só porque são muito pobres as informações sobre produção e uso de fatores de produção, como os próprios dados de crédito são também muito pobres.

Talvez pensando em substituir o papel que só uma análise econométrica pode cumprir (desde que munida dos dados necessários), os autores incluíram no questionário um quesito sobre a "contribuição" do PROCERA na "geração" da produção segundo a percepção dos assentados, o que, evidentemente, simplificaria enormemente nossa tarefa se essa tentativa não fosse destituída de qualquer valor científico. Uma análise dos dados dessa pesquisa encontra-se em Buainain e Souza Filho (1998). Mesmo com todas as suas deficiências, essa pesquisa revelou um resultado que é muito significativo: o valor do "patrimônio doméstico" (fogão a gás, 
camas, automóvel, geladeira, televisão, armários etc.) quintuplicou entre 1993 e 1997, o que denota um elevado nível de gastos monetários dessas famílias em bens de consumo nesse período (de farto PROCERA), com toda certeza incompatíveis com a sua mera atividade produtiva qua assentados da reforma agrária. Tem-se, assim, uma forte evidência quanto ao desvio de recursos do PROCERA em direção a bens de consumo.

Além disso, verificou-se também um grande crescimento no número de animais por assentado, principalmente de pecuária leiteira e suínos, atividades que geram pouca renda monetária. Isso é compatível com o uso do crédito em investimento na produção visando o autoconsumo, conforme também a hipótese considerada neste trabalho.

\section{SUMÁRIO E CONCLUSÕES}

A conclusão principal deste trabalho é de que é muito provável que o PROCERA, após tantos anos em operação, esteja longe de atingir seus objetivos de aumento da produção e da produtividade agrícolas, de aumento da inserção do assentado no mercado em geral e no mercado financeiro em particular, e, assim, torná-lo independente da tutela do Estado, com sua "emancipação". Na verdade, a hipótese mais provável é de que ele tenha gerado uma melhoria artificial de consumo, porque não baseada na melhoria das condições de produção e da inserção do assentado no mercado. Dentro de um programa como a reforma agrária, que visa a melhoria dessas condições para as camadas menos favorecidas no meio rural, através da capacitação, fornecimento de condições iniciais adequadas e, sobretudo, de um estímulo ao esforço de trabalho e de busca de iniciativas por parte do próprio assentado, tornando-o, afinal, capaz de sobreviver e progredir numa economia capitalista e, assim, de ser "emancipado", um programa como tem sido o PROCERA é uma contradição em termos.

Note-se que não se pretende menosprezar a importância da melhoria de bemestar trazida pelo PROCERA por efeito do seu uso direto em bens de consumo ou, melhor ainda, em investimento visando o aumento da produção de auto-consumo. O problema, contudo, é que esses usos do PROCERA, por não gerarem capacidade de pagamento futuro, supõem necessariamente que o Programa consista de uma doação. Se se objetiva realmente isso, então dever-se-ia acoplar ao "pacote" inicial da reforma agrária um montante com esse propósito, sem chamá-lo de crédito. Ao denominar de creditício um programa que de fato é outra coisa, cometem-se dois equívocos graves: 1) cria no assentado a noção distorcida de que crédito é sinônimo de doação ou de calote, e com isso ele nunca se prepara para se integrar à economia capitalista e permanece dependente do Estado e dos grupos políticos que pressionam para manter o Programa intacto; e 2) deixa-se de beneficiar-se a reforma agrária do papel que o crédito - qual um aríete, como explicado antes - pode cumprir para o sucesso econômico dos assentados.

Para fundamentar essa conclusão de que o PROCERA não atingiu seus obje- 
tivos iniciais, o trabalho desceu a detalhes quanto à institucionalidade do PROCERA. Isso incluiu, em primeiro lugar, a própria política de concessão de elevado subsídio e a institucionalidade orçamentária, que se caracteriza pelo não-enquadramento do Programa no sistema que, desde 1988, vigora para os demais programas do Governo na área de crédito rural. Ao lado dessa institucionalidade-mór, sediada em Brasília, o trabalho focalizou também a institucionalidade da seleção dos projetos, concessão dos empréstimos e, principalmente, o sistema de cobrança da dívida e punição/não-punição pela inadimplência. É esse contexto institucional tomado como um todo, onde o que acontece no nível local é inseparável do contexto maior, localizado em Brasília, que é responsável pela baixa eficácia do Programa, para não falar na distorção que ele cria sobre a própria reforma agrária.

É interessante notar que o foco da análise deste trabalho na institucionalidade do Programa se insere numa ampla literatura recente interessada na formulação de políticas de crédito rural especificamente voltadas para os agricultores mais pobres. ${ }^{14}$ É à luz dessa literatura, aliás, que Buainain e Rezende (1998) propõem uma reforma do PROCERA, com o objetivo de torná-lo mais consistente com os seus próprios objetivos.

Apenas para exemplificar a similitude de abordagens, vale mencionar uma das conclusões de Zeller e Sharma (1998, p.21), com base em ampla pesquisa cobrindo nove países na Ásia e na África:

“(...) it is also important for formal institutions to have clear, implementable, and well understood plans for contract enforcement and loan recovery before lending begins. Lack of a credible plan only invites default.”

\section{REFERÊNCIAS BIBLIOGRÁFICAS}

ABRAMOVAY, R. (1994). “Comercialização e Clientelismo.” In A. ROMEIRO e outros (org.), Reforma Agrária: Produção, Emprego e Renda - O Relatório da FAO em Debate. Rio de Janeiro: Vozes/ IBASE/FAO, 1994, pp. 136-142.

BRUNO, R. \& MEDEIROS, L. (1998). Razões das Evasões nos Assentamentos Rurais. Relatório preparado para o MEPF. Convênio FAO/INCRA, Brasília, novembro de 1998.

BUAINAIN, A. M. \& SOUZA FILHO, H. M. (1998). PROCERA: Impactos Produtivos e Capacidade de Pagamento. Relatório Preparado para o MEPF. Convênio FAO/INCRA, Brasília, novembro de 1998.

BUAINAIN, A. M. \& REZENDE, G. C. (1998). PROCERA: Principais Problemas e Propostas de Reforma. Relatório Preparado para o MEPF. Convênio FAO/INCRA, Brasília, novembro de 1998.

GARCIA JR., A. “Geração de Rendas, sua Distribuição e Trajetórias Diferenciais em Assentamentos de Reforma Agrária no Brasil (1985-1989): Comentários sobre um Estudo da FAO”. In A. ROMEI-

\footnotetext{
${ }^{14}$ Ver, especialmente, Hoff e Stiglitz (1990, pp.235-250). Esse e os demais artigos publicados na mesma revista, num número especial sobre “Informação Imperfeita e Mercados de Crédito Rural,” foram depois republicados em Hoff et alii (1993).
} 
RO e outros (org.), Reforma Agrária: Produção, Emprego e Renda - O Relatório da FAO em Debate. Rio de Janeiro: Vozes/IBASE/FAO, 1994.

CASQUES, J. G. \& VILLA VERDE, C. M. (1999). O Financiamento da Reforma Agrária no Brasil. Brasília: IPEA, março de 1999.

HOFF, K. \& STIGLITZ, J. E. (1990). "Introduction: Inperfect Information and Rural Credit Markets - Puzzles and Policy Perspectives." The World Bank Economic Review, vol. 4 n 3 (Sept.1990), pp. 235-50.

HOFF, K., BRAVERMAN, A. \& STIGLITZ, J. E. (1993). The Economics of Rural Organization. Theory, Practice and Policy. Oxford: Oxford University Press, 1993.

IPEA (1998). Instituto de Pesquisa Econômica Aplicada. Coordenação Geral de Política Regional. Política Nacional de Desenvolvimento Regional: Dinâmica Microrregional, Princípios, Diretrizes e Instrumentos (Versão Preliminar). Brasília, março de 1998.

JORGE, W. J., SOUZA, J. G., GEBARA, J. J., SIMON, E. J. \& FERNANDES, B. M. (1997). "Programa de Crédito Especial para a Reforma Agrária (PROCERA): Uma Análise Inicial.” Anais do XXXV Congresso Brasileiro de Economia e Sociologia Rural.” Natal, 4 a 8.8.97, pp. 563-76.

MPO/SEPRE (1998). Ministério do Planejamento e Orçamento. Secretaria Especial de Políticas Regionais. Sistema de Informações Gerenciais - Fundos Constitucionais de Financiamento - FCO FNE - FNO. Ano 1, nº 11. Brasília, agosto de 1998.

OLIVEIRA, M. M. (1997). Pequenos Agricultores e Reforma Agrária no Brasil. Brasília: Publicação do Autor, 1997.

OLIVEIRA, M. M..(1996). Programa Especial de Crédito Rural para Reforma Agrária. Relatório Final de Consultoria. Acordo INCRA/PNUD. Brasília, maio de 1996.

REZENDE, G. C. \& SILVA, M. C. (1993). Os Impactos Fiscal e Monetário do Crédito Rural. Relatório Final de Pesquisa para o PNUD. Rio de Janeiro, novembro de 1993.

ZELLER, M. \& SHARMA, M. (1998). Rural Finance and Poverty Alleviation. Food Policy Repare, International Food Policy Research Institute. Washington, junho de 1998. 